\title{
Preconditioning in Globally Ischemic Isolated Rat Hearts: Effect on Function and Metabolic Indices of Myocardial Damage
}

\author{
Michael Arad ${ }^{1}$, Jan Willem de Jong ${ }^{2}$, Robert de Jonge ${ }^{2}$, Tom Huizer ${ }^{2}$ and \\ Babeth Rabinowitz ${ }^{1}$ \\ ${ }^{1}$ Heart Institute, Sheba M edical Center, Tel Hashomer and Tel-Aviv University, Israel and \\ ${ }^{2}$ Cardiochemical Laboratory, Thoraxcenter, Erasmus U niversity, Rotterdam, The Netherlands \\ (Received 31 January 1996, accepted in revised form 4 June 1996)
}

\begin{abstract}
M. Arad, J. W. De Jong, R. DE Jonge, T. Huizer and B. Rabinowitz. Preconditioning in Globally Ischemic Isolated Rat Hearts: Effect on Function and Metabolic Indices of Myocardial Damage. Journal of Molecular and Cellular Cardiology (1996) 28, 2479-2490. We assessed the effects of ischemic preconditioning on heart recovery and metabolic indices of damage following global ischemia and reperfusion, in relationship to post-ischemic lactate release. Three groups of Langendorff rat hearts were studied: (1) A control group of 40 min global ischemia and $45 \mathrm{~min}$ reperfusion; (2) preconditioning by $5 \mathrm{~min}$ global ischemia and $15 \mathrm{~min}$ reperfusion prior to sustained ischemia and reperfusion; (3) Preconditioning by three episodes of brief ischemia-reperfusion prior to sustained ischemia. Repetitive episodes of brief ischemia-reperfusion were associated with increased reactive hyperemia, decreased release of purines and prostaglandin 6 -keto $F_{1 \alpha}$, lower tissue glycogen but no change in lactate washout. After $40 \mathrm{~min}$ ischemia, release of lactate was $173 \pm 17,196 \pm 6$ and $149 \pm 9 \mu \mathrm{mol} / \mathrm{g}$ in groups 1,2 and 3 , respectively $(P<0.01$, group $2 \vee$ group 3$)$. Preconditioning had no effect on ischemic arrest but had divergent effects on the development and the magnitude of ischemic contracture: delay and attenuation in group 2 but enhanced onset in group 3. Preconditioning provided a dosedependent protection from the increase in left ventricular end-diastolic pressure, reduced the reperfusion release of purine metabolites and of creatine kinase, but neither improved systolic function nor prevented arrhythmia. 6-Keto $F_{1 \alpha}$ production was $87 \pm 13,132 \pm 19$ and $241 \pm 35 \mathrm{pmol} / \mathrm{g}$ in groups $1,2,3$, respectively $(P<0.01$ group $1 \mathrm{v}$ group 3$)$. We conclude that when subjected to prolonged global ischemia, preconditioned isolated rat hearts develop less post-ischemic contracture, lose less purine nucleosides and creatine kinase activity. In addition, preconditioning leads to increased production of prostacyclin. Differences among preconditioning protocols in lactate production seem to be related to the ischemic contracture development, but may not play an ultimate role in attenuation of myocardial damage or improvement of postischemic recovery.

(C) 1996 Academic Press Limited
\end{abstract}

KEY WorDs: Preconditioning; Global ischemia; Isolated rat heart; Arrest; Contracture; Coronary flow;

Reperfusion arrhythmia; Lactate; Prostacyclin.

\section{Introduction}

Preconditioning the myocardium by brief periods of ischemia-reperfusion confers a substantial protection during a subsequent, prolonged ischemic period. In different experimental models of regional ischemia beneficial aspects of preconditioning include: attenuation of structural damage (Murry et al., 1986, 1990), reduction of infarct size (Schott et al., 1990; Liu and Downey, 1992), prevention of arrhythmia during either ischemia or reperfusion (Shiki and Hearse, 1987; Vegh et al., 1990; Hagar

Please address all correspondence to: Babeth Rabinowitz, The Heart Institute, Sheba Medical Center, Tel Hashomer 52621, Israel. 
et al., 1991) and improved functional recovery (Flack et al., 1991). Apparently, preconditioning constitutes a process of adaptation to low-energy states, and is indeed present in various models such as globally ischemic (Cave and Hearse, 1992; Volovsek et al., 1992; Asimakis et al., 1992; Janier et al., 1994), hypoxic (Lasley et al., 1993a) or rapidly paced hearts (Vegh et al., 1991).

Murry et al. (1990) proposed a causal relationship between reduced tissue lactate accumulation and the benefits of preconditioning. Yet, there is considerable controversy concerning the role of anaerobic glycolysis in perpetuation versus attenuation of ischemic damage (Owen et al., 1990) in globally ischemic hearts. The purpose of our study was to assess the effects of ischemic preconditioning on heart recovery and biochemical indices of damage following no-flow global ischemia and reperfusion, in relation to lactate production during the ischemic state.

\section{Materials and Methods}

\section{Preparation}

MaleWistar fed rats received $500 \mathrm{U}$ heparin i.p. and were anesthetized with i.p. pentobarbital sodium $6 \mathrm{mg} / 100 \mathrm{~g}$ body weight. The hearts were rapidly excised and cooled in ice-cold saline until contraction stopped. Then, hearts were mounted on Langendorff apparatus and perfused with oxygenated $\left(95 \% \mathrm{O}_{2}, 5 \% \mathrm{CO}_{2}\right)$, bicarbonate-buffered (pH 7.4), modified Tyrode solution (composition in mM: $\mathrm{NaCl} 128, \mathrm{KCl} 4.7, \mathrm{CaCl} 1.35, \mathrm{NaHCO}_{3} 20.2$, $\mathrm{NaH}_{2} \mathrm{PO}_{4}$ 0.42, $\mathrm{MgCl}_{2}$ 1.05, glucose 10) with a perfusion pressure of $60 \mathrm{mmHg}$. A stiffened latex balloon of ellipsoid form was specially prepared to suit the dimensions of rat left ventricular cavity in order to minimize the artifacts induced by postischemic contracture on pressure measurements (Curtis et al., 1986). The balloon was inflated until left ventricular end-diastolic pressure approached $4 \mathrm{mmHg}$. Systolic pressure of at least $70 \mathrm{mmHg}$ was required for inclusion. The pulmonary artery was cannulated with a 14-gauge catheter for sampling of coronary venous effluent. The $\mathrm{O}_{2}$ content was determined in aortic and venous samples with a Radiometer ABL3 gas analyser. A bipolar electrogram was obtained between the aortic cannula and a platinum electrode, inserted into the right ventricular epicardium. A pacing electrode was positioned on the right atrial appendage. An overdrive atrial pacing (300-330 bpm) was instituted using a Grass 59 stimulator. The whole system was heated by water jacketing and the heart temperature was strictly maintained in the range $36.5-37.5^{\circ} \mathrm{C}$ with the aid of a Ellab Teflon thermistor probe, placed in the right atrial cavity. Measurements of coronary flow were obtained volumetrically and with a Skalar extracorporeal electromagnetic flow-meter posiioned above the aortic cannula. Coronary flow, heart temperature, electrogram, coronary perfusion pressure and left ventricular pressure with its derivative (dP/dt) were continuously recorded on a Graphtec Linearcorder F WR 3701.

\section{Protocol}

Experiments were carried out in three groups $(\mathrm{n}=$ 6-7): (1) An ischemic control group-50 min of baseline perfusion, 40 min no-flow global ischemia and 45 min of reperfusion; (2) A one-cycle ischemic preconditioning group -30 min baseline perfusion, 5 min ischemia with 15 min reperfusion followed by $40 \mathrm{~min}$ ischemia and $45 \mathrm{~min}$ reperfusion; (3) A repetitive, three cycle, ischemic preconditioning group-20 min baseline perfusion, three rounds of 5 min ischemia followed by 10,10 and 15 min reperfusion respectively, and then 40 min sustained ischemia with 45 min reperfusion.

The hearts were paced at the same rate during the whole experiment. The time intervals from onset of ischemia to cessation of effective mechanical contracture (developed pressure $<0.5 \mathrm{mmHg}$ ) and failure of the conductive system were recorded. Functional assessment and measurement of myocardial oxygen consumption were done at baseline, immediately before long-term ischemia and after 30, $45 \mathrm{~min}$ of post-ischemic reperfusion. Spontaneous heart rate was obtained at baseline and after reperfusion measurements, allowing 3 min recovery from the overdrive suppression. Coronary effluent was collected at baseline, before long-term ischemia and continuously during the various reperfusion periods (at minute 1, 2-3, 4-5, 5-10,10-15, 15-30, 30-45). At the end of the experiments the hearts were freeze-clamped, and stored in liquid nitrogen. Additional hearts ( $n=5$ per group), treated according to protocols 1-3, were freeze-clamped just prior to induction of sustained ischemia, for determination of tissue lactate and glycogen .

\section{Biochemical assays}

Nucleosides and oxypurines (adenosine, inosine, hypoxanthine, xanthine, urate) were determined in 
Table 1 Baseline parameters of the experimental groups

\begin{tabular}{|c|c|c|c|c|c|c|c|c|c|c|}
\hline Group & $n$ & $\begin{array}{c}\text { A nimal weight } \\
(\mathrm{g})\end{array}$ & $\begin{array}{l}\text { Heart rate } \\
\quad \text { (bpm) }\end{array}$ & $\begin{array}{c}\text { Pacing rate } \\
\text { (bpm) }\end{array}$ & $\begin{array}{c}\text { CF } \\
(\mathrm{ml} / \mathrm{min} / \mathrm{g})\end{array}$ & $\begin{array}{l}\text { LVEDP } \\
(\mathrm{mmHg})\end{array}$ & $\begin{array}{c}\text { LVDP } \\
\text { (mmHg) }\end{array}$ & $\begin{array}{c}+\mathrm{dP} / \mathrm{dt}_{\max } \\
(\mathrm{mmH} / \mathrm{g} / \mathrm{s})\end{array}$ & $\begin{array}{l}-\mathrm{dP} / \mathrm{dt}_{\max } \\
(\mathrm{mmH} / \mathrm{s})\end{array}$ & $\begin{array}{c}\mathrm{MVO}_{2} \\
(\mathrm{ml} / \mathrm{min} / \mathrm{g})\end{array}$ \\
\hline $\begin{array}{l}1 \\
2 \\
3\end{array}$ & $\begin{array}{l}7 \\
7 \\
6\end{array}$ & $\begin{array}{l}245 \pm 5 \\
261 \pm 5 \\
250 \pm 8\end{array}$ & $\begin{array}{l}262 \pm 17 \\
270 \pm 24 \\
274 \pm 24\end{array}$ & $\begin{array}{l}316 \pm 4 \\
307 \pm 3 \\
314 \pm 5\end{array}$ & $\begin{array}{l}62 \pm 4 \\
73 \pm 5 * \\
57 \pm 4\end{array}$ & $\begin{array}{l}1 \pm 1 \\
0 \pm 1 \\
0 \pm 1\end{array}$ & $\begin{array}{l}85 \pm 5 \\
88 \pm 5 \\
92 \pm 4\end{array}$ & $\begin{array}{l}2340 \pm 120 \\
2400 \pm 100 \\
2620 \pm 80\end{array}$ & $\begin{array}{l}1560 \pm 180 \\
1500 \pm 80 \\
1660 \pm 60\end{array}$ & $\begin{array}{l}0.67 \pm 0.07 \\
0.80 \pm 0.06 \\
0.70 \pm 0.06\end{array}$ \\
\hline
\end{tabular}

Heart rate-spontaneous heart rate; CF-coronary flow (per gram dry weight); LVEDP-left ventricular end-diastolic pressure; LVDP-left ventricular developed pressure; $\pm \mathrm{dP} / \mathrm{dt}_{\max }$ - the positive and negative peaks of the first derivative of the left ventricular pressure; $\mathrm{MVO}_{2}-$ myocardial oxygen consumption (per gram dry weight). bpm-beats per minute. * $\mathrm{P}<0.05 \vee$ group 3 .

coronary effluent samples by HPLC (Smolenski et al., 1990). Lactate in the effluent was measured enzymatically (Sigma Diagnostics, procedure no. 735). Creatine kinase activity was assayed at $37^{\circ} \mathrm{C}$ by the $\mathrm{N}$-acetylcysteine activated DGKCh Method (Merck Diagnostica). The stable metabolite of prostacyclin (6-keto $\mathrm{PGF}_{1 \alpha}$ ) was determined with the DuPont 3[H]-radioimmunoassay kit. Glycogen in tissue homogenate was determined according to Huijing (1970). One $\mathrm{ml}$ homogenate was neutralized with $5 \mathrm{M} \mathrm{NaOH}$ and used for glycogen determination, with rabbit liver glycogen (Boehringer Mannheim $\mathrm{GmbH}$ ) as a standard. The homogenate was centrifuged, the clear supernatant fraction was used for lactate determination according to Gutmann and Wahlefeld (1974). Measurement of dry weight was performed as previously described (De Jong and Huizer, 1985).

\section{Statistics}

All biochemical data were calculated per gram dry weight. Data, presented as mean \pm s.E.M., were compared by analysis of variance, with repeated measures or with Duncan grouping. Inter-group comparison of postischemic measurements was performed in its absolute form or after correction for individual baseline, as appropriate. Statistical significance was accepted at $P<0.05$.

\section{Results}

The experimental groups were well balanced in their baseline characteristics, except for a difference in coronary flow between the two preconditioning groups (Table 1).

\section{Effects of short-term ischemia}

The effects of repetitive ischemia on coronary flow (in group 3) are presented in Figure 1. The reflow

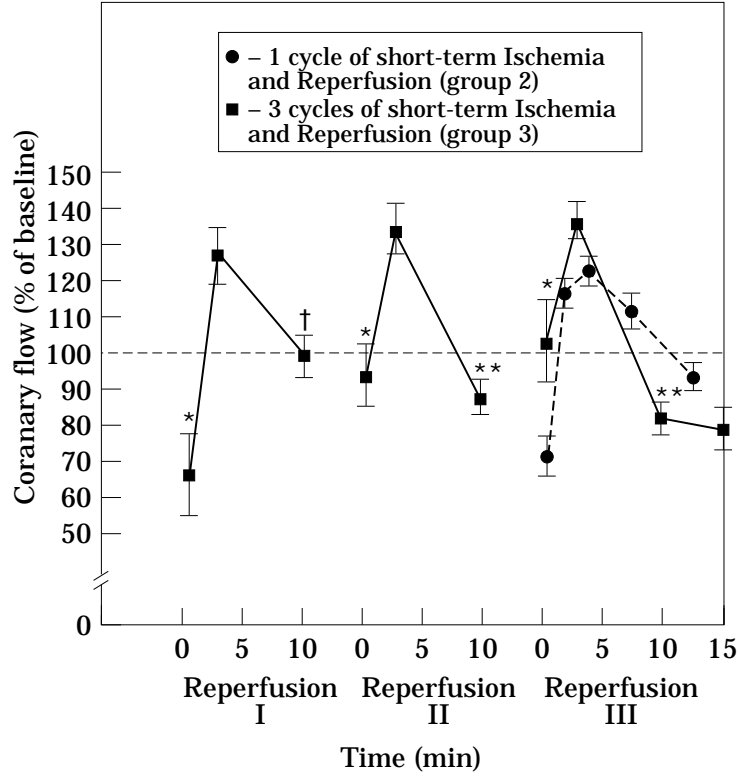

Figure 1 The effects of repetitive short-term ischemia with reperfusion on coronary flow in Langendorff rat heart. The first minute flow increased progressively $(* P<0.001$ in repeated measures ANOVA). The increase in peak hyperemic flow was non-significant, while the coronary flow at $10 \mathrm{~min}$ reperfusion progressively decreased in comparison to baseline $(T P<0.001)$. The broken line illustrates the mean coronary flow during reperfusion following a single episode of $5 \mathrm{~min}$ ischemia in group 2. Note the similarity to the first reperfusion, but the marked difference from the coronary flow in the third repetitive reperfusion in group 3 . The coronary flow in the control group remained at $99 \pm 4 \%$ of the baseline value (not shown).

at the first minute of reperfusion was increased after each consequent cycle while the "plateau" coronary flow decreased. Preconditioning impaired the cardiac function (Table 2): the average decrease in left ventricular developed pressure following short-term ischemia-reperfusion in preconditioning groups 2 and 3 was $15 \%$ and $20 \%$, respectively. The changes in myocardial oxygen consumption were less pronounced. Short-term ischemia resulted in a substantial washout of lactate, prostacyclin and purine metabolites in the coronary effluent, a 
Table 2 Functional parameters before and after 40 min ischemia and reperfusion

\begin{tabular}{lcccccc}
\hline Group & $\mathrm{n}$ & $\begin{array}{c}\text { LVEDP } \\
(\mathrm{mmHg})\end{array}$ & LVDP & \multicolumn{2}{c}{$\begin{array}{c}\mathrm{dP} / \mathrm{dt} \\
(\% \text { of baseline) }\end{array}$} & $\mathrm{MVO}_{2}$ \\
\hline 1 & 7 & $3 \pm 1$ & $98 \pm 3$ & $99 \pm 4 \ddagger$ & $93 \pm 4 \ddagger$ & $97 \pm 3$ \\
2 & 7 & $2 \pm 1$ & $85 \pm 3^{*}$ & $81 \pm 5$ & $75 \pm 4$ & $95 \pm 6$ \\
3 & 6 & $0 \pm 1^{*}$ & $80 \pm 6 \dagger$ & $81 \pm 6$ & $73 \pm 5$ & $83 \pm 6$ \\
Post 40 & min ischemia and reperfusion & & & & \\
1 & 7 & $20 \pm 2$ & $73 \pm 8$ & $72 \pm 7$ & $72 \pm 7$ & $79 \pm 3$ \\
2 & 5 & $13 \pm 3$ & $80 \pm 8$ & $78 \pm 5$ & $76 \pm 7$ & $84 \pm 11$ \\
3 & 5 & $8 \pm 2 \S$ & $73 \pm 4$ & $77 \pm 3$ & $73 \pm 4$ & $84 \pm 11$ \\
\hline
\end{tabular}

LVEDP - left ventricular end-diastolic pressure; LVDP - left ventricular developed pressure; $+\mathrm{dP} / \mathrm{dt}-$ the first derivative of left ventricular pressure; $\mathrm{MVO}_{2}-$ myocardial oxygen consumption. Results of ANOVA with Duncan intergroup comparisons: $* P<0.05,+P<0.01$ v group $1 ; \ddagger P<0.01$ v groups 2 and $3 ; \S P<0.01 \vee$ group 1 .

Note: Two hearts from group 2 and one heart from group 3 did not regain regular rhythm after sustained ischemia.

Table 3 Effects of repeated short-term ischemia and reperfusion on the metabolic markers of ischemic damage

\begin{tabular}{|c|c|c|c|c|c|c|}
\hline Condition & $\begin{array}{c}\text { Purines } \\
(\mu \mathrm{mol} / \mathrm{min} / \mathrm{g}, \mu \mathrm{mol} / \mathrm{g})\end{array}$ & $\begin{array}{r}\text { 6-KE } \\
(\mathrm{pmol} / \mathrm{mi}\end{array}$ & $\begin{array}{l}\mathrm{PGF}_{\alpha} \\
\mathrm{g}, \mathrm{pmol} / \mathrm{g})\end{array}$ & $(\mu \mathrm{mol} / \mathrm{m}$ & $\begin{array}{l}\mathrm{e} \\
\mu \mathrm{mol} / \mathrm{g})\end{array}$ & $\begin{array}{l}\text { Creatine kinase } \\
(\mathrm{U} / \mathrm{min} / \mathrm{g})\end{array}$ \\
\hline $\begin{array}{l}\text { Baseline } \\
\text { Reperfusion cycle }\end{array}$ & $\begin{array}{l}0.07 \pm 0.01 \\
\min 1\end{array}$ & $\operatorname{Min} 1$ & $\begin{array}{l}1.4 \\
\text { Ttotal }\end{array}$ & $\min 1^{3}$ & 6 & $\begin{array}{l}1.1 \pm 0.1 \\
\min 1\end{array}$ \\
\hline $\begin{array}{l}\text { First } \\
\text { Second } \\
\text { Third }\end{array}$ & $\begin{array}{ll}0.61 \pm 0.08 & 2.36 \pm 0.28 * \\
0.65 \pm 0.04 & 1.70 \pm 0.15 \\
0.57 \pm 0.04 & 1.47 \pm 0.13\end{array}$ & $\begin{array}{l}78 \pm 16 \\
79 \pm 19 \\
31 \pm 6\end{array}$ & $\begin{array}{l}198 \pm 21 \dagger \\
169 \pm 34 \\
101 \pm 22\end{array}$ & $\begin{array}{l}41 \pm 4 \\
54 \pm 4 \\
53 \pm 5\end{array}$ & $\begin{array}{l}78 \pm 2 \\
77 \pm 8 \\
77 \pm 8\end{array}$ & $\begin{array}{l}2.3 \pm 0.2 \dagger \\
2.0 \pm 0.2 \\
1.6 \pm 0.5\end{array}$ \\
\hline
\end{tabular}

Values at reperfusion constitute the release at the first minute and the total of the first $5 \mathrm{~min}$, except creatine kinase which was negligible after min 1. Statistical comparisons between reperfusion periods 1-3: $* \mathrm{P}<0.02,+\mathrm{P} 0.05$ (ANOVA for repeated measures).

Purines include purine nucleosides and oxypurines (adenosine, inosine, hypoxanthine, xanthine, urate). Data expressed per gram dry weight.

process taking place within 5 min from the onset of reperfusion. Trace amounts of creatine kinase were detected in the first minute of reperfusion but not later. The release of prostacyclin, purines metabolites and creatine kinase decreased with repeated ischemia-reperfusion while the release of lactate remained stable (Table 3 ). Tissue glycogen stores, measured prior to sustained ischemia, were reduced by three, but not by one episode, of short term ischemia-reperfusion. Tissue lactate in the preconditioned hearts was not significantly different from the control (Table 4).

\section{Ischemic arrest and contracture}

Electromechanical dissociation often preceded the failure of electrical activation of the ventricles. Preconditioning was not associated with any change in the time of arrest of the contractile or electrical activity (Fig. 2). The two protocols of preconditioning had divergent effects on the development and the magnitude of ischemic
Table 4 Tissue lactate and glycogen prior to sustained ischemia

\begin{tabular}{lrc}
\hline Group & $\begin{array}{c}\text { Lactate } \\
(\mu \mathrm{mol} / \mathrm{g})\end{array}$ & $\begin{array}{c}\text { Glycogen } \\
(\mathrm{mg} / \mathrm{g})\end{array}$ \\
\hline 1 & $3.3 \pm 2.0$ & $18.9 \pm 1.0$ \\
2 & $14.3 \pm 8.8$ & $16.0 \pm 1.7$ \\
3 & $14.8 \pm 7.9$ & $6.9 \pm 1.4^{*}$ \\
\hline
\end{tabular}

Data expressed per gram dry weight.

$* P<0.01 \vee$ groups 1 and 2 .

Note the large variation in lactate levels within each group. There were no differences between the groups (ANOVA $\mathrm{P}=$ $0.57)$.

contracture during sustained ischemia (Fig. 3). In group 2, the onset of contracture was delayed and its magnitude diminished significantly. Repetitive preconditioning (group 3) resulted in earlier development of contracture.

Reperfusion after long-term ischemia

There was no significant effect of preconditioning on the coronary flow in comparison with controls 


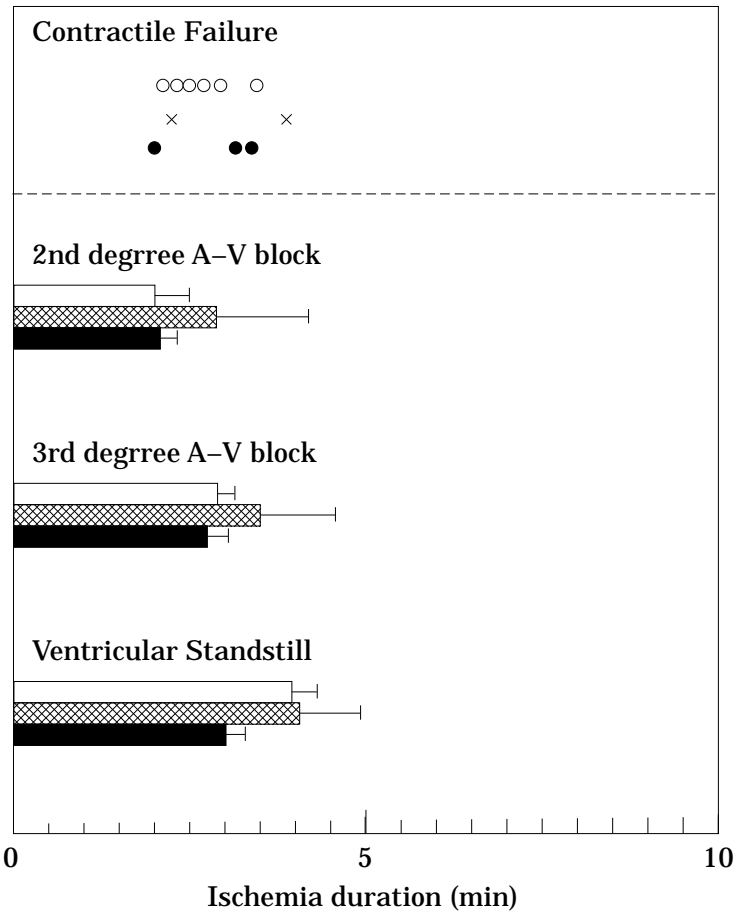

Figure 2 The effect of ischemic preconditioning on the development of ischemic arrest in atrially paced hearts. Open bars-ischemic arrest times (min, mean \pm s.e.M.) in controls (group 1); hatched bars-a single round of ischemic preconditioning (group 2); solid bars-repeated rounds of preconditioning (group 3). Note that contractile failure preceded electrical arrest (ventricular standstill) only in some of the hearts and therefore individual data are shown (open circles-group $1 ; \mathrm{X}$-group 2; solid circles-group 3).

(Fig. 4). The flow at minute 1 was greater in group 2 than in group 3, but afterwards it did not differ among the groups.

Ventricular tachycardia or ventricular fibrillation appeared in all the hearts, approximately within 1 min of reperfusion. Persistent arrhythmia was seen in three preconditioned hearts but none of the controls (NS). The duration of transient arrhythmia did not differ between the experimental groups $(16.9 \pm 3.7,16.0 \pm 4.1$ and $9.0 \pm 5.3$ min in groups 1,2 and 3 , respectively). The spontaneous rate eventually recovered to $95 \pm 8,88 \pm 7,91 \pm 7 \%$ of baseline, respectively $(P=$ N.s. $)$.

Post-ischemic recovery of function usually stabilized after $30 \mathrm{~min}$ of reperfusion. Prolonged arrhythmia delayed the functional recovery, and therefore only measurements at min 45 were accomplished in several hearts. Preconditioning attenuated the increase in left ventricular enddiastolic pressure after prolonged global ischemia. No significant differences were noted in the recovery of the developed pressure or myocardial

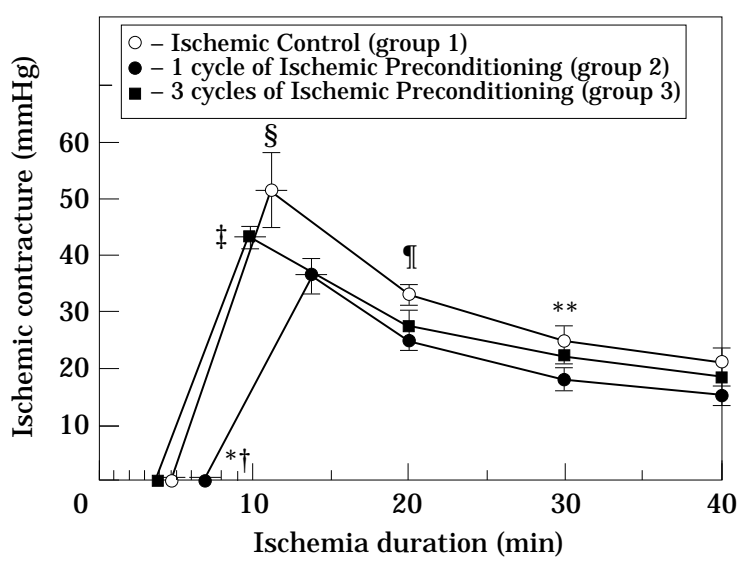

Figure 3 Effects of ischemic preconditioning on the development and time-course of ischemic contracture in globally ischemic isolated rat heart. The data points along each line represent the time of onset, peak contracture and its magnitude after 20,30 and 40 min ischemia. $* P<0.05,+P<0.01$ in ANOVA for time of onset $v$ groups 1 and 3 respectively. $¥ P<0.05$ in ANOVA for time of peak contracture $v$ group $2, \S P<0.05$ for the peak pressure $v$ group 2. After the peak there was a significant decay of pressure with time $(P<0.001$ in repeated measures ANOVA), a borderline group effect $(P=0.067)$ and a non-significant time group interaction. The "group effect" arose from a difference between groups 1 and $2(\mathbb{P}<0.01$, $* * P<0.05$ in one-way ANOVA for contracture at 20,30 min ischemia, respectively).

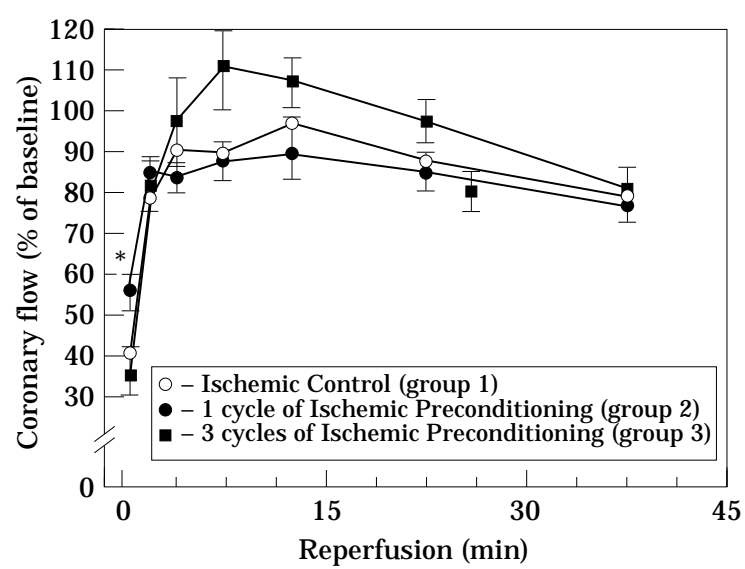

Figure 4 The effect of ischemic preconditioning on coronary flow at reperfusion following sustained global ischemia in the isolated rat heart. The time points constitute the middle of each period of continuous collection. See Table 1 for baseline values of coronary flow. $* \mathrm{P}<0.01$ between groups 2 and 3 .

oxygen consumption (Table 2). The amounts of lactate, prostacyclin, purine metabolites and creatine kinase released following 40 min global 
Table 5 Effects of ischemic preconditioning on the washout of metabolites following 40 min global ischemia

\begin{tabular}{lcccc}
\hline Group & $\begin{array}{c}\text { Lactate } \\
(\mu \mathrm{mol} / \mathrm{g})\end{array}$ & $\begin{array}{c}6-\mathrm{ketoPGF}_{1 \alpha} \\
(\mathrm{pmol} / \mathrm{g})\end{array}$ & $\begin{array}{c}\text { Purines } \\
(\mu \mathrm{mol} / \mathrm{g})\end{array}$ & $\begin{array}{c}\text { Creatine kinase } \\
(\mathrm{U} / \mathrm{g})\end{array}$ \\
\hline 1 & $173 \pm 17$ & $87 \pm 13$ & $12.7 \pm 0.8 \ddagger$ & $203 \pm 44 \S$ \\
2 & $196 \pm 6^{*}$ & $132 \pm 19$ & $9.4 \pm 0.5$ & $128 \pm 22$ \\
3 & $149 \pm 9$ & $241 \pm 35 \dagger$ & $7.6 \pm 0.6$ & $111 \pm 26$ \\
\hline
\end{tabular}

The time periods for calculating the "post-ischemic washout" were determined from the time course of release and were minutes 1-5 for 6-ketoPGF ${ }_{1 x}$, minutes 1-15 for lactate, minutes 1-30 for purines and the whole reperfusion period for creatine kinase.

Purines comprise purine nucleosides and oxypurines (adenosine, inosine, hpoxanthine, xanthine, urate). Data expressed per gram dry weight. Results of ANOVA with Duncan intergroup comparisons:

$* P<0.05 \vee$ group $3 ; \uparrow P<0.01 \vee$ group $1 ; \ddagger P<0.01 \vee$ groups 2 and $3 ; \S P<0.05 \vee$ group 3.

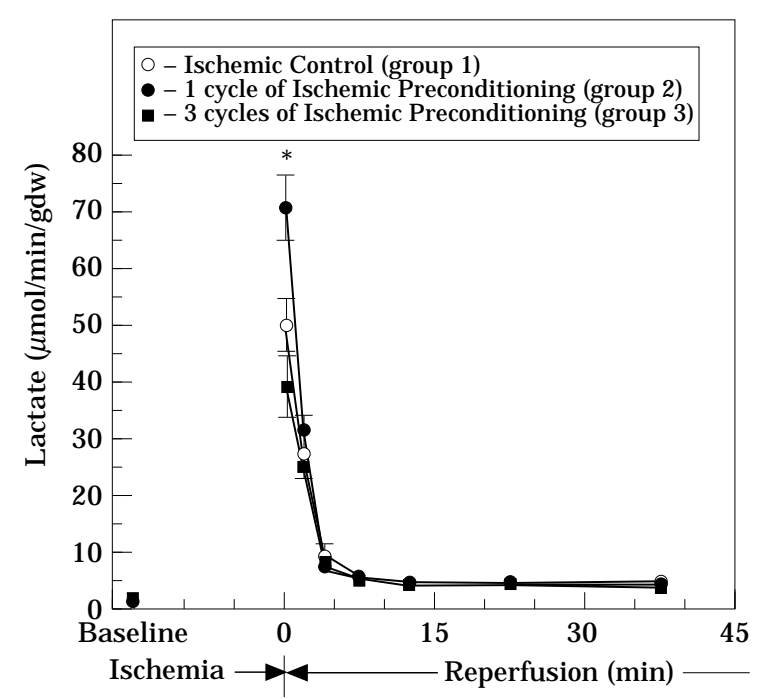

Figure 5 Release of lactate following 40 min global ischemia: comparison between controls and the ischemic preconditioning groups. The time points identify the middle of each period of continuous collection of the coronary effluent. Therelease in all groups and intergroup differences were most pronounced in the first minute of reperfusion (group 2 different from 1 and $3, * P<0.005$ in ANOVA). All differences between the groups disappeared after $3 \mathrm{~min}$ of reperfusion. Coronary effluent lactate returned to baseline levels within 10 to $15 \mathrm{~min}$ (gdwgram dry weight).

ischemia, are compared in Table 5. The metabolite and enzyme release was unrelated to the coronary flow. Lactate release was differently affected by the preconditioning protocols: it was higher in group 2 than in group 3 (both non-significantly different from controls, Fig. 5) The time-course of reperfusion release of inosine and adenosine is given in Figure 6 , and that of creatine in Figure 7. Preconditioning was clearly associated with reduced loss of purine necleosides and creatine kinase. This effect was more pronounced in the group with repetitive preconditioning (group 3). Prostacyclin metabolite was measured only during minutes 1-5 of reperfusion, since our previous
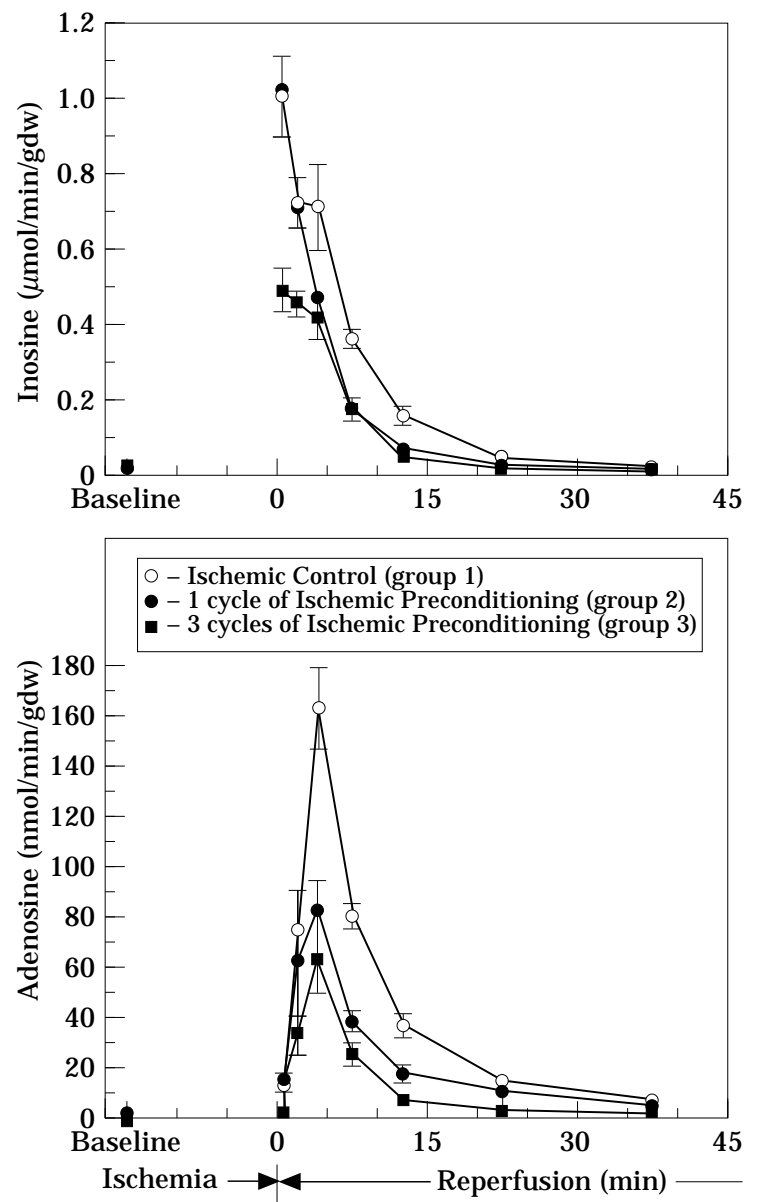

Figure 6 Release of purine metabolites following 40 min global ischemia: inosine and adenosine. Adenosine was found in the coronary effluent in much smaller quantities than inosine and oxypurines (not shown). Adenosine peaked substantially later than inosine. Preconditioning progressively attenuated purine release (see Table 4 for statistical comparison (gdw-gram dry weight).

experiments indicated that the washout is nearly complete at that time. The release of 6-keto PGF ${ }_{1 \alpha}$ was enhanced by ischemic preconditioning and the effect was related to the number of the 


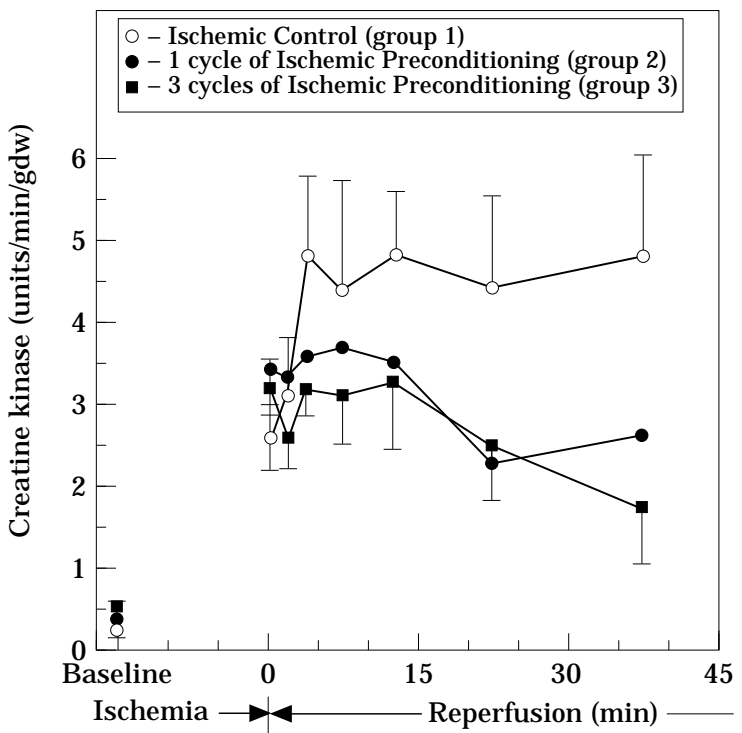

Figure 7 Release of creatine kinase following $40 \mathrm{~min}$ global ischemia. Creatine kinase remained elevated during the whole reperfusion period and showed high variability between the hearts in the time course of release and the total activity lost. The loss of creatine kinase activity tended to be lesser in preconditioned hearts, achieving statistical significance in group 3 (see Table 4) (gdw-gram dry weight).

preceding short-term episodes of ischemia: the increase was slight after a single episode but marked after repetitive cycles of short-term ischemia-reperfusion (Table 5). The amount of glycogen, remaining in the tissue at the end of the experiment, was low $(3.7 \pm 0.3 \mathrm{mg} / \mathrm{g})$ in ischemic controls and even lower in preconditioned hearts. We calculated the cumulative amount of lactate and of purine metabolites released after various ischemias during the whole experiment. The amount of purines lost during all periods of ischemia-reperfusion was equal in the three groups. The overall lactate release was inversely related to the residual glycogen (Table 6).

\section{Discussion}

In isolated hearts, preconditioning manifests by reduced infarct size (Liu and Downey, 1992) and prevention of arrhythmias during coronary occlusion and reperfusion (Hagar et al., 1991. Protection in rat hearts, undergoing no-flow global ischemia was shown by Cave and Hearse (1992), using preconditioning with 5 min of both ischemia and reperfusion, in the isolated working rat heart model. They found a functional benefit with normothermic global ischemia up to $25 \mathrm{~min}$, and with hypothermic ischemia up to $160 \mathrm{~min}$ duration, but no sparing of tissue high energy phosphates. Volovsek et al. (1992) preconditioned rat hearts by repetitive episodes of either 2 or 5 min ischemia, thereby improving functional recovery and reducing lactate and enzyme release after $20 \mathrm{~min}$ ischemia. Other authors (A simakis et al., 1992; Steenbergen et al., 1993; Lasley et al., 1993a) had similar findings with preconditioning in the Langendorff model, using one or more episodes of 5 min ischemia and 5-10 min reperfusion intervals.

Our results indicate protection by preconditioning manifested by reduction of aden ine nucleotide catabolism, reduced leakage of creatine kinase and attenuation of postischemic increase in end-diastolic pressure. However, other components of ischemia-reperfusion damage like systolic function, reperfusion arrhythmias and myocardial oxygen consumption were not significantly affected.

\section{Coronary flow}

Reversible ischemia increases coronary resistance and imparis vasodilator responsiveness (Bolli et al., 1990). In our study, the hyperemic flow increased with successive bouts of brief ischemia (Fig. 1). There was no attenuation of no-reflow following sustained ischemia, as described by Asimakis et al.

Table 6 Residual tissue glycogen in relation to the overall lactate release

\begin{tabular}{llll}
\hline Group & $\begin{array}{c}\text { Glycogen } \\
(\mathrm{mg} / \mathrm{g})\end{array}$ & $\begin{array}{c}\text { Total Lactate } \\
\text { release } \\
(\mu \mathrm{mol} / \mathrm{g})\end{array}$ & $\begin{array}{c}\text { Total purine } \\
\text { release } \\
(\mathrm{nmol} / \mathrm{g})\end{array}$ \\
\hline 1 & $3.7 \pm 0.3^{*}$ & $298 \pm 27 \dagger$ & $12.8 \pm 1.0$ \\
2 & $2.6 \pm 0.2$ & $432 \pm 8$ & $12.7 \pm 0.6$ \\
3 & $2.3 \pm 0.3$ & $480 \pm 33$ & $12.9 \pm 0.5$ \\
\hline
\end{tabular}

Total lactate/purine release- sum of the quantities found in effluent following various episodes of short and long-term ischemia. Data expressed per gram dry weight.

$* P<0.01$ between groups 1 and $3, P<0.05$ between groups 1 and 2 .

$\dagger P<0.01$ v groups 2 and 3. 
(1992). In their study, the inner-layer underperfusion ought to be attributed to an excessive end-diastolic pressure in the ischemic controls. We used lower basal balloon pressures. Post-ischemic diastolic pressures were also lower, permitting a substantially better reflow. We did not find a re lationship between the metabolites determined in the coronary effluent and the the coronary flow. It may only be postulated that a complex relationship between the products of the cyclooxygenase pathway, adenosine, endothelium-derived (nitric oxide, endothelin) as well as mechanical factors regulate the vascular tone in the preconditioned heart.

\section{Ischemic arrest}

Rapid induction of cardiac arrest prior to the onset of ischemia permits the maintenance of higher energy levels during ischemia, delays the rise in $\left[\mathrm{Ca}^{2+}\right.$ in $]$ and the development of ischemic contracture, and leads to a better recovery upon reperfusion (Hearse et al., 1976; Steenbergen et al., 1990). Someauthors (Murry et al., 1990; Nakagomi et al., 1993) suggested that contractile failure might occur earlier in preconditioned hearts. In our study preconditioning had no prominent effect on atrioventricular conduction, contractile failure or ventricular electrical arrest. Therefore, early arrest of electrical or mechanical activity is neither necessary, nor does it contribute to the protective effect of preconditioning in globally ischemic isolated rat heart.

\section{Reperfusion tachyarrhythmia}

Reperfusion tachyarrhythmia occurred in all the hearts (following 40 min global ischemia). The lack of the anti-arrhythmic effect of preconditioning in our global ischemic setting is in disagreement with the well-documented antiarrhythmic effect of preconditioning in regionally ischemic hearts (Shiki and Hearse, 1987; Hagar et al., 1991). The ability of the myocardium to generate arrhythmias at reperfusion is considered to indicate tissue viability, is usually highest with ischemia of 5-20 min and declines afterwards (Manning and Hearse, 1984). Reperfusion arrhythmogenesis is related to the size of ischemic zone: the incidence of ventricular fibrillation increased to $100 \%$ when the ischemic region was enlarged to above $45 \%$ of the ventricle (Curtis and Hearse, 1989). Therefore, an antiarrhythmic effect of preconditioning, manifested during regional ischemia or reperfusion, will not necessarily suffice to protect globally ischemic hearts. Our further studies in global ischemia suggest that preconditioning does not attenuate, but alters the temporal relationship of reperfusion tachyarrhythmias (Oxman et al., 1994).

\section{Cardiac function}

The ability of preconditioning to improve postischemic function is a matter of controversy. Regional contractility was not preserved following preconditioning and $60 \mathrm{~min}$ ischemia in dog (Ovize et al., 1992). A markedly reduced extent of necrosis following long-term global ischemia was not associated with improved post-ischemic functional recovery in isolated rabbit hearts (Sandhu et al., 1993). However, as mentioned above, studies in rat usually demonstrated functional protection by preconditioning. Our experiments utilized atrial overdrive pacing to standardize the heart rate during assessment of contractile performance. Postischemic diastolic dysfunction was attenuated without improvement of systolic contraction. Neither developed pressure, nor spontaneous heart rate, or oxygen consumption were significantly affected (Table 2).

The shorter reperfusion intervals used by other authors in the course of preconditioning could be responsible for their better functional results. Short reperfusion after brief ischemia is associated with a greater degree of stunning than in this study. The energy demand of pre-ischemic myocardium may govern ATP breakdown during subsequent ischemia and thus affect the outcome of preconditioning (De Jong et al., 1995). In the current study the recovery of developed pressure was remarkably good. Prolonged ischemic episodes, as used here, damage many of the hearts beyond their ability to recover in the working heart system. The extent of damage is underestimated by measuring the isovolumic pressure development in the non-ejecting Langendorff model of heart perfusion. Because of these limitations, the beneficial effect on systolic function could be inadequately expressed.

Relationship with ischemic lactate production

Neely and Grotyohann (1984) improved ischemic tolerance of isolated rat hearts by anoxic glycogen depletion. However, these findings could not be reproduced in rabbit hearts (Lagerstrom et al., 1988). The role of glycolysis in attenuating ischemic damage was re-emphasized in studies involving 
global ischemia (Owen et al., 1990; Steenbergen et al., 1990).

In open-chest dogs (Murry et al., 1990; Wolf et al., 1993) and in isolated rat hearts (Volovsek et al., 1992; A simakis et al., 1992), protection after repetitive preconditioning coincided with reduced glycogen stores and diminished lactate accumulation in totally ischemic myocardium. In contrast, preconditioned isolated rabbit hearts undergoing low-flow ischemia were protected in association with enhanced glycolysis and greater lactate production (Janier et al., 1994).

In our study, ischemic lactate production was represented by cumulative reperfusion release of lactate. This may underestimate tissue lactate accumulation during ischemia and does not account for glycolysis and lactate metabolism taking place at reperfusion. We believe our approach is valid since: (a) our hearts were not immersed and no lactate loss occured to the surrounding medium; (b) It may be assumed that no differences existed between the groups in the ratio of lactate to pyruvate + alanine during global ischemia (Janier et al., 1994); (c) The time course of lactate release on reperfusion (Fig. 5) indicates a washout from the previously ischemic tissue; (d) Lactate remaining in tissue after prolonged reperfusion in this model is negligible in comparison to the ischemic levels (Tani and Neeli, 1990b).

Preconditioning per se did not necessarily lead to reduced lactate release (Fig. 5 and Table 5). A combination of two factors may explain a somewhat increased lactate washout in group 2: (a) substantial glycogen replenishment occured during the first reperfusion period; (b) although still controversial (Dale et al., 1991), adenosine released during preconditioning ischemia might be responsible for stimulating the glycolytic flux afterwards (Lasley and Mentzer, 1993b, Wyatt et al., 1989). Repeated brief ischemia (in group 3 ) depleted tissue glycogen stores (Table 4 ) thereby reducing the rate of anaerobic glycolysis during the subsequent prolonged ischemia.

Thus, we compared two protocols of preconditioning, significantly different (and divergent relative to control) in their rate of lactate release. Both preconditioning groups appeared to have ben eficial effects on postischemic diastolic pressure and enzyme release. Three rounds of short-term global ischemia-reperfusion provided more protection than a single event. This concurred with treatment-induced depression of myocardial function. However, the beneficial effects of preconditioning on myocardial salvage cannot be explained entirely as a result of reduced oxygen consumption prior to sustained ischemia (Table 2, also Miura et al., 1991; Murry et al., 1991). Indeed, "prestunning" seems to decrease myocardial oxygen consumption less than it impairs function (Laster et al., 1989; Benzi and Lerch, 1992).

These data suggest that the reduction of the ischemic damage in preconditioned hearts is not necessarily dependent on the effect of preconditioning on myocardial energy consumption or ischemic lactate production. A pparently, there was still not as much protection as others have seen. Therefore the present study suggests that it is possible to observe a protective effect of ischemic preconditioning in the absence of a decrease in anaerobic glycolysis, but the magnitude of the protective effect is less than in protocols that reduce energy consumption, lactate production and acid accumulation.

\section{Ischemic contracture}

Ischemic contracture development was markedly different between the preconditioning groups: it was attenuated in group 2 but appeared earlier in group 3 (Fig. 2). Earlier onset of contracture was reported in rat hearts preconditioned by $5 \mathrm{~min}$ ischemia or hypoxia and 10 or 5 min reperfusion (Asimakis et al., 1992; Lasley et al., 1993a). Janier and coauthors (1994) reported attenuation of contracture during low-flow ischemia in rabbit heart preconditioned by $3 \mathrm{~min}$ ischemia and 12 min reperfusion.

The onset of contracture is associated with ATP depletion and actin-myosin rigor bond formation (Owen et al., 1990). Contracture development in preconditioned hearts may be related to their glycolytic flux. The apparent disagreement between the findings obtained in various studies may be reconciled, if we assume that the effect of repeated ischemia on contracture is mediated by glycolysis, and is dependent on the model, the number of short-term ischemic episodes and the duration of the reperfusion intervals.

The elevated left ventricular diastolic pressure at later stages of ischemia and at reperfusion, behaves differently from early ischemic contracture. This post-ischemic contracture reflects diastolic functional impairment, generally attributable to cytosolic free $\mathrm{Ca}^{2+}$ overload (Steenbergen et al., 1990; Tani and Neely, 1990). Preconditioning apparently constitutes an effective method for alleviation of ischemia-reperfusion associated calcium overload (Steenbergen et al., 1993). 
Aldenosine and total purine

A denosine and total purine loss was attenuated in the preconditioned hearts, indicating decreased nucleoside breakdown during sustained ischemia (Fig. 6). This confirms previous observations in rabbit hearts (De Jong et al., 1994) and probably indicates a more favorable myocardial energy state following preconditioning (Zucchi et al., 1990). On the other hand, the pattern in rat contrasts the marked increase in adenosine and 5'-nucleotidase activity in preconditioned canine hearts (Kitakaze et al., 1993). Several investigators have already shown that preconditioning in rat, in contrast to rabbit and dog, is not mediated by adenosine (Liu and Downey, 1992; Li and Kloner, 1993).

\section{Prostacyclin release}

To the best of our knowledge, the effect of preconditioning on the cardiac release of prostacyclin has not yet been reported. Hearts synthesize and release various eicosanoids during and following ischemia, even of short duration (Karmazyn, 1986; Okada, 1991; Rabinowitz et al., 1992). Prostacyclin is the main metabolite of arachidonic acid, produced under these circumstances (Van Bilsen et al., 1989). Early synthesis of prostaglandins by the anoxic/ ischemic heart is apparent prior to development of damage and probably constitutes a compensatory response (Alexander et al., 1975; Woditsch and Schror, 1992). Endogenous prostaglandins seem to be involved in both reactive hyperemia following brief ischemia (Okada, 1991) and in endotheliumdependent vasoconstriction (Ito et al., 1991). The involvement of products of the cyclooxygenase pathway in prevention of ischemic arrhythmias, similarly to exogenous lloprost, suggests participation of prostacyclin in preconditioning (Vegh et al., 1990). Other investigators, also using cyclooxygenase inhibitors in preconditioning experiments, could not confirm a role for prostaglandins in limiting infarct size or arrhythmia (Li and Kloner, 1992). The present study (Tables 3 and 5) provides evidence that: (a) cardiac adaptation to repeated short-term ischemia involves a decrease in prostacyclin production; (b) the protection during and following prolonged ischemia coincides with an enhanced prostacyclin release. Our data do not prove a link between prostacyclin and the protection afforded by ischemic preconditioning. We believe that the effects of preconditioning on prostaglandin synthesis warrant further investigations, since these mediators may be involved in attenuation of microvascular stunning (Richard et al., 1994) and other forms of cardioprotection.

\section{Conclusions}

In this model of protracted global ischemia in isolated rat hearts, preconditioning leads to an augmented prostacyclin release after sustained ischemia. Preconditioning is manifested by a decrease in postischemic contracture and biochemical evidence of myocardial salvage, but not necessarily by prevention of arrhythmia or improved systolic contraction. Anaerobic glycolysis appears to be necessary for attenuation of ischemic contracture; however it may not play an ultimate role in the effect of preconditioning on myocardial damage or post-ischemic recovery.

\section{Acknowledgements}

We are indebted to Mrs Liz Kezer, Selma Nieukoop, Ella Elazar and Rodica Klein for their skillful, valuable assistance. Mrs Yael Villa M.Sc. is acknowledged for performing the statistical analysis.

\section{References}

A lexander RW, Kent KM, Pisano JJ, Keiser HR, Cooper $T$, 1975. Regulation of postocclusive hyperemia by spontaneously synthesized prostaglandin in the dog heart. J Clin Invest 55: 1174-1181.

A simakis GK, InNERs-M cBride K, M EdeLLin G, Conti VR, 1992. Ischemic preconditioning attenuates acidosis and postischemic dysfunction in isolated rat heart. Am J Physiol 263: H887-H894.

BENZI RH, LERCH R, 1992. Dissociation between contractile function and oxidative metabolism in postischemic myocardium. Attenuation by Ruthenium Red administered during reperfusion. Circ Res 71: 567576.

Bolli R, Triana F, Jeroudi MO, 1990. Prolonged impairment of coronary vasodilation after reversible ischemia. Evidence for microvascular "stunning". Circ Res 67: 332-343.

Cave AC, Hearse DJ, 1992. Ischaemic preconditioning and contractile function: studies with normothermic and hypothermic global ischaemia. J Mol Cell Cardiol 24: 1113-1123.

Curtis MJ, McLeod BA, Tabrizchi R, Walker MJ, 1986. An improved perfusion apparatus for small animal hearts. J Pharmacol M eth 15: 87-94.

Curtis MJ, Hearse DJ, 1989. Reperfusion induced arrhythmias are critically dependent upon occluded zone size: relevance to the mechanism of arrhythmogenesis. J M ol Cell Cardiol 21: 625-637. 
Dale WE, Hale CC, Kin HD, Rovetto MJ, 1991. Myocardial glucose utilization. Failure of adenosine to alter it and inhibition by the adenosine analogue $\mathrm{N}^{6}-(\mathrm{L}-2-$ phenylisopropyl)adenosine. Circ Res 69: 791-799.

De Jong JW, Huizer T, 1985. Reduced glycolysis by nisoldipine treatment of ischemic heart. J Cardiovasc Pharmacol 7: 497-500.

De Jong JW, Cargoni A, Bradamante S, Curello S, Janssen M, Pasini E, Ceconi C, Bunger R, Ferrari R, 1995. Intermittent $v$ continuous ischemia decelerates adenylate breakdown and prevents norepinephrine release in reperfused rabbit heart. J Mol Cell Cardiol, in press.

Flack JE, Kimura Y, Engelman RM, Rousou Ja, I yengar , JoNES R, DAS DK, 1991. Preconditioning the heart by repeated stunning improves myocardial salvage. Circulation 84(Suppl. III): III369-III374.

GutMan I, W AHLEFELD AW, 1974. L-(+)-Lactate determination with lactate dehydrogenase and NAD. In: Bergmeyer HU, ed., M ethods of Enzymatic Analysis ( 2 nd edit), vol 3, Verlag Chemie: Weinheim/A cad Press: New York, 1468-1472.

Hagar JM, Hale SL, Kloner RA, 1991. Effect of preconditioning ischemia on reperfusion arrhythmias after coronary artery occlusion and reperfusion in the rat. Circ Res 68: 61-68.

Hearse DJ, Stewart DA, Braimbridge MV, 1976. Cellular protection during myocardial ischemia. The development and characterization of procedure for induction of reversible ischemic arrest. Circulation $\mathbf{5 4}$ 193-202.

HuijING F, 1970. A rapid enzymic method for glycogen estimation in very small tissue samples. Clin Chim Acta 30: 567-572

Ito T, Kato T, Imama Y, Muramatsu M, Shimizu K, A sano $\mathrm{H}$, Okumura $\mathrm{K}, \mathrm{H}$ ashimoto $\mathrm{H}$, Satake T, 1991. Regulation of vascular tone by endothelium-derived contracting factor (EDCF). In: Inoue M, Hori M, Imai $\mathrm{S}$, Berne RM, eds. Regulation of coronary blood flow. Tokyo: Springer-Verlag, 217-229.

Janier MF, Vavoverschelde JLJ, Bergmann SR, 1994 Ischemic preconditioning stimulates anaerobic glycolysis in the isolated rabbit heart. Am J Physiol 267: H1353-H1360.

Karmazyn M, 1986. Contribution of prostaglandins to reperfusion-induced ventricular failure in isolated rat hearts. Am J Physiol 251: H133-H140.

Kitakaze M, HoRi M, TaKashima $S$, Sato $H$, Inoue $M$, KAMADA T, 1993. Ischemic preconditioning increases adenosine release and 5'-nucleotidase activity during myocardial ischemia and reperfusion in dogs. Implications for myocardial salvage. Circulation 87: 208215.

Lagerstrom CF, W Alker WE, TAegtmeyer $H, 1988$. Failure of glycogen depletion to improve left ventricular function in the rabbit heart after hypothermic ischemic arrest. Circ Res 63: 81-86.

LASLEy RD, A NDERSON GM, M ENTZER RM JR, 1993a. Ischaemic and hypoxic preconditioning enhance postischaemic recovery of function in the rat heart. Cardiovasc Res 27: 567-570.

LASLEy RD, M ENTZER RM JR, 1993b. Adenosine increases lactate release and delays onset of contracture during global low flow ischaemia. Cardiovasc Res 27: 96-101.

Laster SB, Becker LC, A mbrosio G, J acobus WE, 1989. Reduced aerobic metabolic efficiency in globally "stunned" myocardium. J Mol Cell Cardiol 21: 419426.

LI Y, KLONER RA, 1992. Cardioprotective effects of ischemic preconditioning are not mediated by prostanoids. Cardiovasc Res 26: 226-231.

LI Y, KLONER RA, 1993. The cardioprotective effects of ischaemic "preconditioning" are not mediated by adenosine receptors in rat hearts. Circulation 87: 16421648.

LIU Y, Downey JM, 1992. Ischemic preconditioning protects against infarction in rat heart. Am J Physiol 263: H1107-H1112.

M ANNING AS, HeARSE DJ, 1984. Reperfusion-induced arrhythmias: Mechanisms and prevention. J Mol Cell Cardiol 16: 497-518.

Miura T, Goto M, Urabe K, Endoh A, Shimamoto K, I IMURA O, 1991. Does myocardial stunning contribute to infarct size limitation by ischemic preconditioning? Circulation 84: 2504-2512.

Murry CE, Jennings RB, Reimer KA, 1986. Preconditioning with ischemia: a delay of lethal cell injury in ischemic myocardium. Circulation 74: 1124-1136.

Murry CE, Richard VJ, Reimer KA, Jennings RB, 1990. Ischemic preconditioning slows energy metabolism and delays ultrastructural damage during a sustained ischemic episode. Circ Res 66: 913-931.

Murry CE, Richard VJ, Jennings RB, Reimer KA, 1991. Myocardial protection is lost before contractile function recovers from ischemic preconditioning. Am J Physiol 260: H796-H804.

Nakagomi A, Saito T, Kimura $Y$, Tamura $Y$, Miura $M$, 1993. Altered electrical and metabolic response of reperfused myocardium to ischaemia after recovery from preceding ischaemia: evidence for ischaemia sensitized myocardium. Cardiovasc Res 27: 571-577.

N EeLY JR, GrotyohanN LW, 1984. Role of glycolytic products in damage in ischemic myocardium. Dissociation of adenosine triphosphate levels and recovery of function of reperfused ischemic hearts. Circ Res 55: $816-824$

ОкаDА T, 1991. Hypoxia-induced change in prostaglandin production and coronary flow in isolated rat heart. J M ol Cell Cardiol 23: 939-948.

Ovize M, PrZYKLENK K, Hale SL, Kloner RA, 1992. Preconditioning does not attenuate myocardial stunning. Circulation 85: 2247-2254.

Owen P, Dennis S, OpIe LH, 1990. Glucose flux regulates onset of ischemic contracture in globally un derperfused rat hearts. Circ Res 66: 344-354.

Oxman T, Arad M, Kaplinsky E, Rabinowitz B, 1994. The type of the brief preconditioning influences the development of reperfusion arrhythmias (Abstract). J M ol Cell Cardiol 26: LIX.

Rabinowitz B, Arad M, Elazar E, KLeIN R, Har Zahav $Y$, 1992. Epicardial versus endocardial "in mirror" changes in prostaglandin synthesis after short periods of ischemia and reperfusion. Eicosanoids 5: 163-167.

Richard V, KaefFer N, Tron C, Thuillez C, 1994. Ischemic preconditioning protects against coronary endothelial dysfunction induced by ischemia and reperfusion. Circulation 89: 1254-1261.

Sandhu R, Diaz RJ, W ILSON G], 1993. Comparison of ischemic preconditioning in blood perfused and buffer perfused isolated heart models. Cardiovasc Res 27: 602607.

Schott RJ, Rohmann S, Braun ER, Schaper W, 1990. 
Ischemic preconditioning reduces infarct size in swine myocardium. Circ Res 66: 1133-1142.

SHIKI K, HeARSE DJ, 1987. Preconditioning of ischemic myocardium: reperfusion induced arrhythmias. Am J Physiol 153: H1470-H1476.

Smolenski RT, Lachno DR, Ledingham SJM, Yacoub MH, 1990. Determination of sixteen nucleotides, nucleosides and bases using high-performance liquid chromatography and its application to the study of purine metabolism in hearts for transplantation. J Chromatogr 527: 414-420.

Steenbergen C, Murphy E, W atts JA, London RE, 1990. Correlation between cytosolic free calcium, contracture, ATP, and irreversible ischemic injury in perfused rat heart. Circ Res 66: 135-146.

Steenbergen C, Perlman ME, London Re, Murphy E, 1993. Mechanism of preconditioning: Ionic alterations. Circ Res 72: 112-125.

TANI M, NeELY JR, 1990. Mechanisms of reduced reperfusion injury by low $\mathrm{Ca}^{2+}$ and/or high $\mathrm{K}^{+}$. Am J Physiol 258: H1025-H1031.

TANI M, N EELY JR, 1990b. Intermittent perfusion of ischemic myocardium. Possible mechanisms of protective effects on mechanical function in isolated rat heart. Circulation 82: 536-548.

Van Bilsen M, Engels W, van der Vusse GJ, Reneman RS, 1989. Significance of myocardial eicosanoid production. M ol Cell Biochem 88: 113-121.

Vegh A, Szekeres L, Parratt JR, 1990. Protective effects of preconditioning of the ischaemic myocardium involve cyclo-oxygenase products. Cardiovasc Res 24: 1020-1023.

Vegh A, Szekeres L, Parratt JR, 1991. Transient ischaemia induced by rapid atrial pacing results in myocardial preconditioning. Cardiovasc Res 25: 1051-1053.

Volovsex A, Subramanian R, Reboussin D, 1992. Effects of duration of ischemia during preconditioning on mechanical function, enzyme release and energy production in the isolated working rat heart. J $\mathrm{M}$ ol Cell Cardiol 24: 1011-1019.

W oditsch I, Schror K, 1992. Prostacyclin rather than nitric oxide is a tissue protective factor in myocardial ischemia. Am J Physiol 263: H1390-H1396.

W olfe CL, Sievers RE, Visseren FLJ, Donnelly TJ, 1993. Loss of myocardial protection after preconditioning correlates with the time course of glycogen recovery within the preconditioned segment. Circulation 87: 881-892.

W yATT DA, EDMunds MC, Rubio R, Berne RM, LASLEy RD, M ENTZER RM JR, 1989. A denosine stimulates glycolytic flux in isolated perfused rat hearts by $A_{1}$-adenosine receptors. Am J Physiol 257: H1952-H1957.

Zucchi R, Limbruno U, Poddighe R, M ariani M, Ronca $G, 1990$. Purine release from isolated rat heart: A new approach to the study of energy metabolism. J M ol Cell Cardiol 22: 815-826. 